\title{
Closing the attainment gap - a realistic proposition or an elusive pipe-dream?
}

\begin{abstract}
The attainment gap associated with socio-economic status is an international problem that is highly resistant to change. This conceptual paper critiques the drive by the Scottish Government to address the attainment gap through the Scottish Attainment Challenge and the National Improvement Framework. It draws upon a range of theoretical perspectives but principally examines the problem through the lens of SteinerKhamsi's (2014) concepts of 'reception' and 'translation' of policy and through examination of the international and national (Scottish) policy contexts. The paper argues that, rather than focussing narrowly upon attainment outcomes, an holistic approach should be adopted which takes account of the economic, social and relational constraints which impact upon families in poverty, calling for a systems-level approach. 'Schools cannot go it alone': there is a need to focus upon a wide range of public policy to redress inequalities in society. Whilst the Scottish Government has looked to the London/City/National Challenge as a potential solution to the problem, the complexities and limitations of policy borrowing need to be understood. Higher Education Institutions, government agencies, local authorities and schools need to work in partnership to develop research informed practice which will impact upon learning outcomes for all children and young people.
\end{abstract}

Dr Joan G Mowat, School of Education, University of Strathclyde

Social justice, politics

This paper focuses upon the attainment gap associated with socio-economic status and the work of the Scottish Government to address this problem, placing the discussion within a global context. It is a conceptual paper that draws from and integrates a range of fields - social justice, policy, school effectiveness and leadership. It is not a literature review and is not intended to provide comprehensive coverage of each respective field. It draws upon a range of theoretical perspectives but principally examines the problem through the lens of Steiner-Khamsi's (2014) concepts of reception and translation of policy and the international, UK (principally English) and national (Scottish) policy contexts. 
It draws from a range of empirical and theoretical papers, international reports and Scottish Government policy documents, using a process of best-evidence synthesis (Harlen and Schlapp 1998) to select the literature, based on criteria such as the relevance, credibility of the source and currency of the work. The selected literature focuses upon the areas of poverty, attainment, children's health and wellbeing, policy and leadership, with a specific focus upon systems leadership. Key documents are the Scottish Government policies relevant to the Scottish Attainment Challenge (see 'The Scottish Context') and the range of reports emanating from the Organisation for Economic Cooperation and Development (OECD) focussing upon equity in education (Schleicher 2014; OECD 2007; OECD 2013).

The paper critiques the approach of the Scottish Government with regard to how it conceptualises and addresses the stated problem. It argues principally that the problem cannot be addressed by focussing primarily, and almost exclusively, on the school as the agent of change and that the starting point for change should be addressing endemic inequalities in society. It also argues that the complexities and limitations of policy borrowing are not fully understood, as reflected in Scottish government policy.

But, why should a specific focus upon the Scottish context be relevant to the international reader? Firstly, because the problems facing Scottish education are universal and apply at a global level across school systems. Secondly, the persistence of problems at an international level associated with inequitable outcomes for children that have been highly resistant to change. Thirdly, the increasing prominence of the OECD reports on education performance (highlighting inadequacies in school systems and fostering competitiveness among nation states) and influence of comparative studies such as the two McKinsey reports comparing and contrasting 
school systems across the globe (Barber, Whelan, \& Clark, 2007; Mourshed, C. Chijioke, \& M. Barber, 2010) have led to government's seeking solutions to inadequacies in their performance by policy borrowing in an unquestioning and uncritical way. Coffield (2012) argues, 'There is not sufficient acknowledgement of the complexities involved in attempting to derive lessons from another country (never mind 25), because of enormous differences in educational history, politics, socioeconomic conditions, culture, and institutional structures.' (137).

This paper uses the Scottish context as a case study to illuminate the issues at a global level, highlighting the limitations and constraints of policy borrowing, such that a much more cautious and critical approach can be adopted. It draws to attention some of the tensions within the system world-wide, such as those relating to how the problem of inequitable student outcomes is framed by policy makers; the constraints and complexities of a system pursuing competing imperatives within a neo-liberal agenda; and the limitations of and difficulties around the responses forwarded at international, national and local level to the problem. As such, it addresses an important imperative at a crucial point in time which has implications not only for the direction of Scottish policy but is of global significance as countries across the world wrestle with this problem.

After an initial examination and exploration of the problem at global, UK and Scottish levels, the paper problematises policy borrowing as a potential solution to closing the attainment gap before examining the implications for systems leadership and the school as the lever for change, drawing conclusions from the discussion.

\section{Examining the problem}

\section{Global level}


The quest to address inequities in educational outcomes associated with socioeconomic status is not new, is enduring and is of global significance (Caro and Mirazchiyski 2011; Ainscow 2012; Dickerson and Popli 2012; Smyth and Wrigley 2013; The New Policy Institute 2013; Schleicher 2014b; Sosu and Ellis 2014; Valant and Newark 2016). Over the past three decades, income inequalities have been growing within most OECD countries and are at their highest level in thirty years (OECD 2016b). Whilst the country where pupils attend school outweighs social class in impacting on pupil achievement (Schleicher 2014a), social class is closely related to student and school characteristics and exerts a 'powerful influence on learning outcomes' (Ibid, 19). Within a culture of performativity in which nation states, fuelled by international league tables, compete to be 'the best' (Ball 2015, 2003; Ringarp and Rothland 2010; Feniger and Lefstein 2014; Clapham, Vickers, and Eldridge 2016; Hodgson and Spours 2016; Moore and Clarke 2016; Solomon and Lewin 2016), is policy borrowing the answer to addressing the inequitable educational outcomes that are associated with socio-economic status?

In a quest to drive improvement in educational outcomes at a global level, the OECD, drawing on data deriving from the Programme for International Student Assessment (PISA), identifies the characteristics of top-performing education systems as having high expectations of all pupils with a clear focus on equity. Such systems invest in their staff through equipping them with proven pedagogical skills and through the promotion of teacher autonomy and creativity.

However, Harris et al. (2015) cite a range of commentators who are critical of the over-simplistic ontological underpinnings of comparative international reports, the underlying premise of which is that the replication of strategies in new contexts will lead automatically to better outcomes. These, they argue, fail to take account of the 
complexity of school systems and the contextual and cultural boundaries in which they operate.

Further, whilst there has been an increasing focus upon equity in OECD reports, Bøyum (2014) critiques the restricted understandings of 'equity' represented within them, being perceived as a 'means to an end' (economic prosperity) rather than something of value and worth in its own right. He questions whether the quest for equitable educational outcomes sits comfortably with a neo-liberal agenda focused upon privitisation, competition and accountability through standardised tests, as represented in PISA (an argument to be pursued at a later point).

The OECD report, 'Excellence, Equity and Inclusiveness in Education ..' (Schleicher 2014a), observes that many economic and social problems, such as early pregnancy, are linked to lower educational attainment but fails to recogise that it may be underlying societal and structural isses (such as inequality) which underpin both. Indeed, decades of research indicate that 'the school effect' (what schools can achieve when account is taken of other variables) is very limited - within the region of $8-15 \%$ (Bangs, Macbeath \& Galton 2011).

The problem is framed in terms of what education systems, schools and teachers can do as a means of redressing inequalities in society rather than how redressing inequalities in society can lead to more equitable educational outcomes. This does not mean to say that the solutions forwarded within the report are not of value or worth (for example, the focus upon high quality early-years provision) but that it is not helpful to examine schooling in isolation of wider societal issues.

The framing of the problem in this way also leads potentially to a 'blame culture' in which neighbourhoods, communities, parents, 'inadequate individuals', schools, their leaders and teachers are held to be accountable both for the 
circumstances in which they find themselves and for the solutions to the problem (Smyth and Wrigley 2013) rather than critiquing the neo-liberal, 'quasi-market', 'survival of the fittest' agenda. Smyth and Wrigley are critical of a model of school improvement based upon a mantra of "If they can do it, why can't you?" and highlight the inadequacies of the data which often drive this process (cc. p.39-140).

Wilkinson and Pickett (2010) attest that it is not poverty per se which impacts upon educational performance within nation states but inequalities in society. On a range of indicators - health and social problems, children's wellbeing - the correlation with levels of social inequality is of much greater statistical significance than the correlation with average income. The prevalance of these problems is greater in areas of deprivation and much greater in more unequal societies which indicates that it is the dispersal of income within nations (ie. relative poverty ${ }^{\mathrm{i}}$ and social stratification) which is the issue: "what matters is where we stand in relation to others in our own society' (Kindle location 423). Drawing from Willms (1999), they make the case that higher educational performance is dependent upon creating more equal societies which implies that the problem is being approached from the wrong direction. Indeed, they go beyond this to claim that, whilst the country you come from makes a difference in terms of educational outcomes, for children from disadvantaged backgrounds with lower educated parents, these differences are compounded.

Yet, in contrast to this, amongst the highest performing education systems (according to PISA results [OECD 2016a]) are systems such as Singapore where social inequity (but not inequity in educational outcomes) is amongst the highest in developed nations (Wilkinson and Pickett 2010) and in which a high proportion of children are classified as 'resilient' ie. performing beyond what might be expected of them with regards to socio-economic status. This might imply that there are other 
factors at play such as cultural values and attitudes towards education and schooling within the population.

This discussion has raised some critical issues about how the problem is understood at an international level and how these understandings frame the potential policy solutions. It has also highlighted tensions and contradictions between policy agendas seeking equity on one hand but promoting privitisation, competition and accountability on the other. The school effectiveness and improvement movements have demonstrated that school improvement arises not as a response to changing structures and systems, which international comparators almost inevitably lead us towards, but through engagement with the school community and changing culture (Harris et al., 2015, drawing from Reynolds [2010]).

\section{The UK Context}

A range of studies within the UK examining the impact of poverty on educational outcomes for children and young people has shown that it extends beyond formal educational outcomes to factors such as dispositions towards learning and school; feelings of anxiety and lack of confidence about school; and perceptions of discrimination as children try to negotiate the economic, social and relational constraints associated with poverty (Hirsch 2007; Ridge 2011).

Persistent rather than episodic poverty, mediated by parental investment in their children's learning, has a greater impact on children's cognitive development, extending far beyond the period during which children may have experienced it (Dickerson and Popli 2012). Seven year-old children who have experienced persistent poverty are more than 10 percentile ranks lower in achieving educational benchmarks than other children. Children with Special Educational Needs and Difficulties who also live in poverty are less likely than other children to gain access to high quality 
early years provision and, subsequently, high achieving schools. They were also more likely to be socially isolated or excluded from mainstream schooling (Shaw et al. 2016).

Within the United Kingdom, addressing inequity in educational outcomes takes place against a background of attempts to eradicate child poverty and to reduce health inequalities (Department for Work and Pensions 2007; Policy First 2012; Scottish Government 2014a; Smith 2015). Many would argue, however, that these attempts are counter-productive because they take place within a neo-liberal agenda in which education has become increasingly marketised (Ainscow, Booth, and Dyson 2006; Brunila 2011; Grimaldi 2012; Graham and Slater 2015; Solomon and Lewin 2016) and within a policy context in which what is given on one hand is taken away by the other (Seith 2015; Hill et al. 2016).

The London Challenge was introduced in 2003 as a response to the poor performance of London schools in national league tables. Key components of the challenge were the introduction of a bespoke leadership programme; a focus on the quality of pedagogy in London schools; the expansion of cultural activities for pupils; and the detailed analysis of data, comparing schools sharing similar characteristics and demographics. The programme was designed to build on what were perceived to be identified strengths, such as the Academies programme (see critique to follow), and was supported by a team of highly experienced advisers and London Challenge Project Managers (Tomlinson 2013).

Many successful outcomes were reported for the programme and the 'ingredients' for its success identified (Kidson and Norris 2014). The impact of the programme was such that, according to Day and Hackman (2012), performance in poorly performing London schools had improved more rapidly than schools with 
similar characteristics nationally. The programme was subsequently rolled out through the City Challenge by means of 'Keys to Success' in Manchester and 'Pathways to Achievement' in the Black Country (Hutchings et al. 2012; Ainscow 2015) and across the country through the National Challenge. A subsequent development was the identification of 'teaching schools', serving as beacons of excellence and as a hub for the professional training of teachers and headteachers (Ainscow et al. 2016). However, whilst some of the schools within the lower quartiles demonstrated significant improvement, outcomes for the City Challenge were more variable than those for the London Challenge (Hutchings et al. 2012).

The programme is not without its critics and some commentators have challenged its findings, attributing its success to a range of other variables such as the ethnic mix of pupils within the London boroughs (Burgess 2014); and the performance of pupils within the Primary sector (Greaves, Macmillan, and Sibieta 2014). Other commentators have disputed the finding that the Academies programme (with which the London Challenge is closely associated) had 'ended decades of failure' (Day and Hackman 2012), claiming that there is no evidence of greater 'added value' for academies rather than comprehensives once account has been taken of other variables (Wrigley 2012).

The above discussion might indicate that there is a need for caution in seeing the London Challenge as a potential solution to 'closing the gap' within Scottish schools.

\section{The Scottish Context}

In Scotland, the attainment gap associated with socio-economic status is established before school and persists and, indeed, expands, over the course of formal schooling. 
This is reflected in significantly lower educational outcomes on leaving school and subsequent destinations after school for young people in poverty. One fifth of Scottish children are living in poverty. At age three, both in relation to vocabulary and problem-solving, statistically significant gaps have emerged between children in the highest and lowest income quartiles which manifest themselves at age five in 13 month and 10 month differentials respectively (Bradshaw 2011).

During formal schooling, both in terms of numeracy and literacy, the attainment gap widens over time (Scottish Government, 2012, 2013). At the end of formal schooling, the differential in attainment is the equivalent of 4 ' $\mathrm{A}$ ' grades in Scottish Higher examinations, reflected in a higher proportion of young people from affluent homes attaining a qualification at age $22-23(63 \% \mathrm{v} 14 \%)$. For low attainers, staying on at school beyond compulsory schooling was the best indicator of gaining intermediate or advanced qualifications beyond school but this was correlated more with children from more advantaged backgrounds and those whose parents had higher levels of qualifications (Howieson and Iannelli 2008; Sosu and Ellis 2014).

Whilst the gap in attainment is narrowing over time (for example, the differential in children's vocabulary scores at age three over a six year period had reduced), the earlier patterns, referred to above, are still in evidence. A higher incidence of social, emotional and behavioural difficulties (18\% v 3\%) and lower levels of life satisfaction ( $29 \% \mathrm{v} 19 \%$ ) have been recorded at age eight between those in the highest and lowest income quintiles (Scottish Government 2015a). The above indicates the scale of the problem. It highlights the need to focus on the whole child and the circumstances which impact on the child's learning, social and emotional development and attitudes to school rather than simply narrowly defined attainment outcomes. 
A range of education policies to promote social justice, children's wellbeing and inclusion has been put in place over the past two decades including those focussing upon meeting additional support needs (SEED 2001; Scottish Government 2012); addressing poverty (Scottish Government 2014a) and inequalities in the early years (Scottish Government 2015a); child protection (SEED 2002); supporting looked after and accommodated children (Scottish Government 2016d); 'Excellent, ambitious schools' - government funding to support innovation (SEED 20024); widening access to further and higher education (Scottish Government 2016e); and the most recent publication focussing upon 'closing the gap' associated with socio-economic status (Scottish Government 2016a) - an action plan for implementation. This has been complimented by a series of reports from Her Majesty's Inspectorate of Education (HMIE). However, given the amount of activity and resources directed towards the problem, reducing the attainment gap is proving to be heavily resistant to change.

Two key reports on Scottish education, commissioned from the Organisation for Economic Co-operation in Developed Countries (OECD), have driven the efforts of the Scottish Government to raise achievement and address the attainment gap. The initial report (SEED 2007) describes the Scottish Education system as one of the most high performing and equitable in the world. However, it identifies the socio-economic status of pupils as being a major determinant of attainment in international tests. The concentration of multiple disadvantages in schools serving poor communities intensifies the effects of socio-economic status as does the predominantly academic culture in schools which may not meet the individual needs of students (15-16).

The latter report, a review of progress in relation to the implementation of Curriculum for Excellence (the national curriculum), identifies many positives within 
the system, such as an upward trend in school leaver destinations. In contrast, it highlights negative trends in key areas such as reading and mathematics and the widening achievement gap as children progress through the system. Negative trends are also identified in relation to a range of 'softer' indicators, such as liking school and a sense of belonging (Scottish Government 2015b). This is of significance as a sense of belonging is co-related with a range of positive academic, psychological, behavioural and social outcomes for children and, conversely, with negative indicators such as poor mental health, anxiety and depression (Prince and Hadwin 2013; Riglin et al. 2013; Author 2015).

In response to the aforementioned reports, a range of initiatives and interventions has been directed towards addressing the achievement gap in Scotland the most prominent of which is the announcement of the Scottish Attainment Challenge, modelled on the London challenge, supported by an initial investment of $£ 100$ million from the Scottish Government with subsequent additional funding. This funding takes a variety of forms from funding directed towards local authorities and schools with high concentrations of deprivation; an 'innovation fund' open to all local authorities; and, more recently, to an 'equity fund', additional funding directed towards individual schools, allocated on the basis of free-school meal entitlement (Education Scotland Website).

This body of work has been supported by the appointment nationally of Attainment Advisors; the establishment of a 'National Improvement Hub' which can be accessed by teachers and school leaders; and publication of the National Improvement Framework for Scotland (cc. figure 1)(Scottish Government 2016c) and an action plan to support it - 'Delivering Excellence and Equity in Education' (Scottish Government 2016a). 


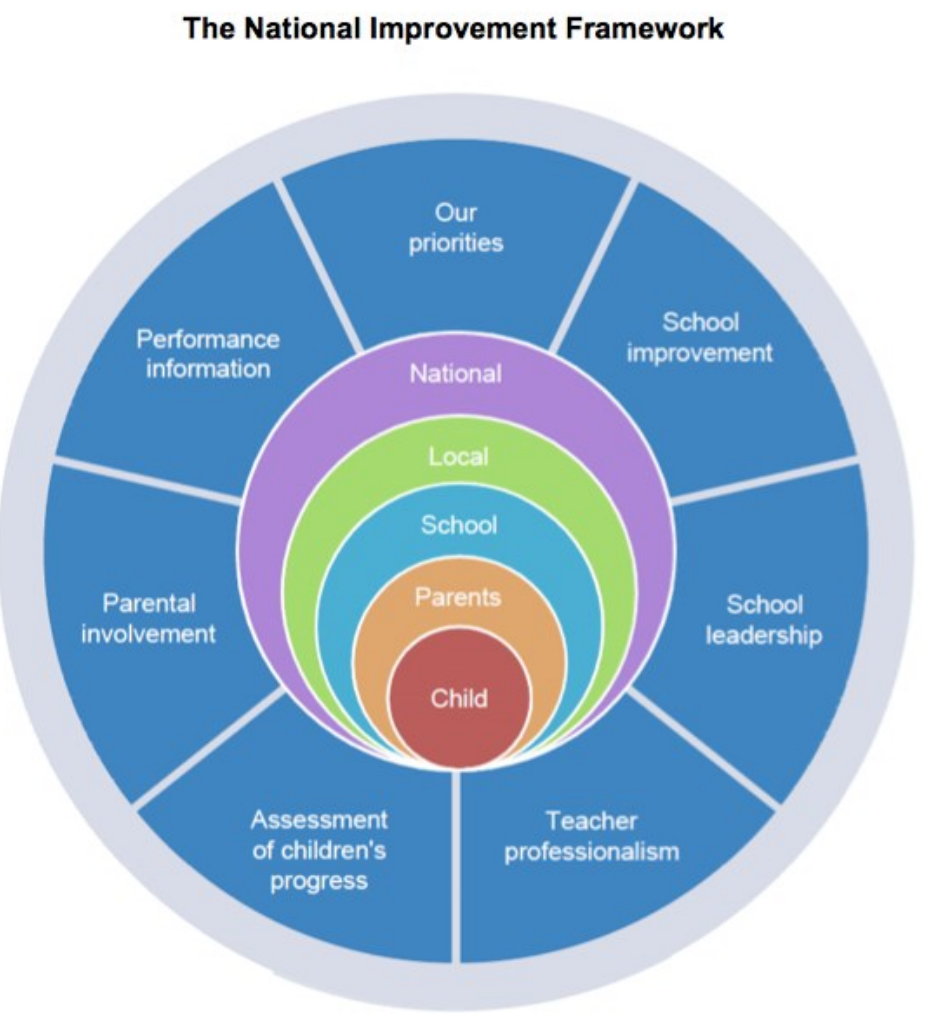

Figure 1: The National Improvement Framework (C) Crown Copyright

A recently published Research Brief, commissioned and published by the Scottish Government, focussing upon what schools can do to address the poverty gap identifies five guiding principles - putting the child at the centre; addressing individual needs; building respect and trust; balancing autonomy and accountability; and enabling flexibility and creativity (Marcus 2016). However, the scale, complexity and difficulty of this task should not be under-estimated. Few international studies have been able to record successful outcomes for school improvement at district level for secondary schools (Menter et al. 2009). As can be illustrated through the work of MacBeath and colleagues, even extensive programmes to tackle low performing schools in which there had been considerable government investment demonstrated no greater gains than comparator schools over a five year period. This, the research team attributed to a range of factors amongst which were the need for sustainable, 
longterm investment; the negative impact of a 'show-quick-results-at-any-cost mentality' (138) and the need to combat local infrastructures which do not address wider systems issues through more joined-up social and economic policy (MacBeath et al. 2007).

It's clear from the above discussion that childhood poverty, as it manifests itself in Scotland, has a significant impact upon children's lives and plays a significant role in the under-achievement of many children. The Scottish Government is clearly committed to addressing the problem and has directed significant funding and resources towards it. However, lessons from the past indicate that this may not be sufficient to address problems which are endemic in society and which require longterm investment and engagement. This raises questions as the extent to which schools are able to impact upon the problem and whether, or not, policy borrowing is the right solution.

\section{Policy borrowing as a potential solution to the problem}

Having outlined the nature and complexity of the problem at international, UK and national levels and critiqued aspects of policy, this part of the paper initially examines the growing international imperative (driven to a large extent by organisations such as the OECD) to 'borrow policy' from one national context to another and explores how policy borrowing is understood and the theories underpinning it. Thereafter, SteinerKhamsi's concepts of reception and translation of policy will be used to interrogate Scottish Government policy in its quest to 'close the gap', drawing from insights gained from a range of contexts from the international to the local.

Education policy, in an era of globalisation, is described by Rizvi and Lingard (2010) as multi-dimensional, multi-layered and occurring at multiple sites. The 
increasing prominence of international league tables ${ }^{\mathrm{ii}}$ and the reports which emanate from them have put pressure on education systems throughout the world to 'perform' and to be seen to be out-performing other nations (Ball 2003, 2015; Ringarp and Rothland 2010; Dumay and Dupriez 2014; Polesel, Rice, and Dulfer 2014, Hodgson and Spours 2016). Allied to the growth of the knowledge economy (Brunila 2011), these international comparators have become highly influential in shaping educational policy (MacBeath 2013, Bøyum 2014; Hodgson and Spours 2016). Increasingly it is observed that governments seeking to find policy solutions to problems turn to policy borrowing as a potential solution, facilitated by strengthening global networks and the marketing of policies across the world (Dolowitz and Marsh 2000). As such, there is a drive at a global level not only to 'import' policy but also to 'export' it.

Within Scotland, the growing imperative to address inequalities in health, life expectancy, education and income has been a further driver towards seeking systems solutions which 'work' from across the world and from within the sister nations of the United Kingdom. However, as comparative studies show, policy borrowing too often ignores or underplays the importance of the cultural and political context, bringing into question the notion of 'transfer' of policy and practice from one context to another (Feniger and Lefstein 2014; Steiner-Khamsi 2014).

Policy borrowing, described by Philips and Ochs (2004) as the 'conscious adoption in one country of policy observed in another', is often perceived as the 'solution' to the above phenomena. Central to policy borrowing are the key questions, 'Can country X solve its educational problems by adopting policy or practice deemed to be successful in country Y? And if so, how is such policy or practice transferred and implemented?' (Philips 2006, 553). 
Hodgson and Spours (2016) make a distinction between policy borrowing and policy learning. The former they describe as being a highly political process which is motivated by a desire by nation states to justify existing policy, to implement highly selective samples of 'best practice' and to 'transfer' policy across nations. The latter they describe as 'processes that focus on modes of governance, curriculum, implementation and the conduct of policy itself across national boundaries; across time and involving different policy actors.' (514) They compare and contrast two contrasting approaches to policy learning - restrictive and expansive. Restrictive approaches are characterised by competition; centralisation; the identification and borrowing of 'best practice'; and a culture of policy innovation. In contrast, expansive approaches are characterised by collaborative cultures; decentralised policy based upon a partnership model; identification of common issues and 'good practice' in comparable contexts; and a reflective culture which understands the history of policy innovation within a specific context.

Steiner-Khamsi (2014) identifies two key approaches towards policy borrowing - a normative approach in which 'best practice' is identified and transferred; and an approach which examines why and when certain policies and practices are identified as being 'best practice'. There are two key aspects of both approaches: reception (which examines the initial contact with the global education policy and the selection of this area - why it is considered to be apposite) and translation (concerned with policy into practice). With regard to the former approach (normative), there is almost an assumption that such transfer is not only desirable but inevitable, yet consideration needs to be given to the evidence base on which such conclusions are drawn (as per the previous discussion). 
Steiner-Khamsi (2014) argues that policy borrowing is not as rational as it may initially appear: it is 'deeply rooted in political, social, and economic decisions' (162) and will only happen if it fits with the domestic agenda. For it to happen at all, there are certain conditions to be met: political willingness; problem recognition; and the mobilisation of external funding. It is how these three variables interact with each other which creates a 'policy window' for change.

This discussion has highlighted two principal things - firstly, that, within the context of globalisation, nations increasingly turn to policy borrowing as a solution to identified problems and, secondly, policy borrowing (and the distinction between policy borrowing and learning) can be understood in a variety of ways.

Drawing from insights gained from the Scottish, UK and international contexts, the following discussion interrogates the Scottish Attainment Challenge with regard to the reception and translation of policy.

\section{Reception of policy}

To return to the Scottish Attainment Challenge, the questions needs to be asked, why this specific approach? And why now? What factors have come together to create the context and conditions for this policy change or, as Steiner-Khamsi (2014) writes, this 'policy window'? The author (drawing from Kingdon [1995]) identifies the convergence of three streams as being the conditions under which change is most likely to happen: the problem stream (recognition of the problem); the policy stream (availability of solutions); and the political stream (new developments in the political realm) (156).

With regard to the problem stream, it can be seen from the previous discussion that there has been growing recognition within Scotland of the endemic nature of the attainment gap associated with socio-economic status brought into sharp relief by the 
report commissioned by the Joseph Rowntree Foundation (Sosu and Ellis 2014) and international (OECD) reviews.

With regard to the policy stream, OECD publications have enabled nations and states to compare and contrast educational performance and to draw on case studies of good practice. Such work often leads to an international platform for the work, making it even more influential. Within the UK, the highly publicised London Challenge and subsequent developments have been influential in guiding the Scottish Government's thinking about potential solutions to the problem.

With regard to the political stream, inequitable educational outcomes are not just associated with socio-economic status: they transcend a range of areas such as disability, race, ethnicity, sexuality and gender (Ainscow 2012; Mirza 2010; Taylor 2010) so why focus on this specific gap? Further, as outlined in the introduction to this paper, the attainment gap associated with socio-economic status has a long provenance and is enduring yet it has only fore-fronted Scottish educational policy recently. Valant and Newark (2016) attest that public opinion impacts upon public policy to a significant extent and can shape policy makers' agendas and decisions. It could be surmised that the Scottish Government is tapping into a broader stream of consciousness in which the Scottish people seek a more equitable society. 'Closing the gap' may be perceived as being one of the least contentious means of achieving this aim as it shifts the focus (and accountability associated with it) towards local authorities and schools and, as previously discussed, away from broader public policy addressing structural and systemic inequality.

It can also be seen that the timing of this intervention is crucial. SteinerKhamsi (2006) argues that policy borrowing doesn't occur solely because other policies are seen to be better but because the very act of borrowing policy impacts 
upon domestic policy conflict: 'there must be a window of opportunity or receptiveness towards innovation in the local context for a new reform to resonate' (671). Likewise, Halpin and Troyna (1995) consider that it is more about legitimising a course of action within the recipient nation. Cross-national borrowing is more likely to occur within a context of 'protracted policy conflict' (Steiner-Khamsi 2006) as characterised by the Scottish Referendum and, more recently, the fallout from BREXIT, raising consciousness of Scottish issues and a desire within the Scottish Government to 'make its mark' and be seen to be addressing these issues.

It is also driven by a culture of performativity and economic imperatives to ensure that Scotland is able to compete effectively within a global economy and world market (Scottish Government 2016c), heavily influenced by the commodification of knowledge and international comparators (Ball 2003, 2015; Polesel, Rice, and Dulfer 2014; Clapham, Vickers, and Eldridge 2016; Moore and Clarke 2016; Solomon and Lewin 2016)). However, the Scottish Government, whilst looking to the London Challenge for potential solutions to the problem, has adopted a 'pick and mix' approach ("We like the look of this, but we're not having that"), aligning with what are perceived to be Scottish values (such as egalitarianism) and practices. (For example, the Scottish Government's rejection of diversification of schooling and the Academies programme.)

Thus, it can be seen that a range of circumstances and factors have converged to create the 'policy window' for the reception of the policy by the Scottish Government.

\section{Translation - policy into practice - tensions, potential difficulties and barriers}

The translation of policy from inception to practice is highly complex involving multiple layers of interpretation - what Adams (2016) describes as 'the interpretations 
of interpretations' (294). Halpin and Troyna (1995) observe that policy borrowing is most likely to be successful when there is 'some synchrony between the characteristics of the different education systems involved and the dominant political ideologies promoting reform within them.' (304) The 'pick and mix' approach alluded to above is an indication of the disparity in educational policy between Scotland and the wider UK and is indicative of differing philosophical stances and ideologies more generally (Wrigley 2012).

For many years, England has been the epitome of high-stakes accountability, often playing leapfrog with the USA. It represents an extreme of centralised surveillance, with schools organised as a quasi-market and supervised through a punitive combination of external inspection, the use of test data to name and shame schools and ultimately closure and privatisation. Other parts of the UK such as Wales and Scotland have been moving away from this and developing fundamentally different educational policies. (5)

In their comparative study of the four nations which make up the United Kingdom, Hodgson and Spours (2016) comment upon a rejection of educational policies from south of the border both on educational and political grounds - " "not the Scottish way"' (518) - but also on the basis of the historical, egalitarian philosophy of Scottish education which saw the 'lad o'pairts' (Gatherer 2013) make his way in life. According to the authors, the Scottish approach towards policy learning has both restrictive and expansive dimensions but leans towards the latter with its emphasis upon more democratic and consultative approaches to policy development.

Scotland largely rejected the neo-liberal policies associated with the Thatcher era that were subsequently built on by successive governments (Baron 2001; Hodgson and Spours 2016). As previously noted, the privatisation of public schooling through the Academies programme has been firmly rejected in Scotland. There is a firm commitment towards comprehensive schooling: 'We are committed to a publicly owned and run, comprehensive education system in Scotland - a mutual system, not a market system - which supports every child to achieve' (Scottish Government 2016a, 
10). Indeed, the Scottish Government's consultation on school governance (now closed) had explicitly ruled out the setting up of privately-owned academies or grammar schools (Scottish Government 2016b).

In examining in greater detail the components of the London Challenge, which built on previous centrally-directed Government initiatives in England, how much affinity is there between the top-down approaches adopted once schools had been identified by OFSTED as being in special measures or requires significant improvement and the generally more consensual and collaborative approach towards school improvement in Scotland? What issues does this raise in relation to the discourse of 'failing schools', school closures and the privatisation associated with this? To what extent is the solution to be found in the parachuting in of a 'Super Head'? As research has consistently shown, in seeking to adopt approaches from elsewhere, it is important to take account of the cultural and local context, as a lack of fidelity to the approach which is being 'borrowed' or 'transferred' (or an approach which 'cherry picks' aspects of an approach) offers no guarantee that what may be gained in the initial context will hold true within a different context:

... it is not inevitable that transfer will be successful. As such, while transfer may shape policy change, it may also lead to implementation failure. This means that, even if we can regard policy transfer as a key explanatory variable in the development of many policies, we must also recognize that it is important to follow each policy through to see whether uninformed, incomplete or inappropriate transfer leads to policy failure. (Dolowitz \& Marsh 2000, 23)

The above highlights the potential dangers of policy borrowing and some of the necessary conditions for it to be successful as well as those conditions which act as barriers to successful transfer.

However, there is much within the London Challenge which resonates within the Scottish context and there are parallels between the approaches advocated within the London (and later the City and then the National) Challenge and former Scottish 
initiatives such as 'Excellent, Ambitious Schools'. It is clear, even at this early stage, that the Scottish response is not so centralist or directive as that within the wider UK and combines a systems-led approach with local responsiveness to local problems, fostering distributed leadership. However, the extent to which this becomes reality may be mediated by power relations and tensions between public bodies and the roles of local authority officers, National Attainment Advisors, Higher Education Institutions, teacher unions, school leaders and teachers on the ground (a complex arena to be negotiated); the degree to which policy becomes refracted as it is interpreted afresh at each level of the system; and competing and contradictory narratives, ideological positions and policy initiatives.

In conclusion, cultural differences, reflected within the distinctiveness of Scottish educational policy, systems and structures, may potentially act as impediments to the translation of policy into practice but it is also important to consider that responsiveness to the local context is also a key aspect of successful transfer and of successful change management (Fullan 2003; Hargreaves and Fullan 2012, MacBeath et al. 2007; MacBeath 2012). This may imply that it is a matter of balance and degree.

\section{The Implications for Leadership}

A clear message to emerge from a range of international reports and research is the importance of high quality leadership in effecting systems change (Pont, Nusche, and Moorman 2008; Harris 2010; OECD 2013; Schleicher 2014b, Spillane 2013). As previously observed, there is abundant evidence that many attempts to reform schools have had little long-term impact, much of which may be attributed to an ill-conceived model of change, too heavily reliant on schools to 'deliver outcomes' while ignoring deeper-lying systemic issues. Systems reform, of necessity, will require collective 
capacity and a commitment to change at all levels of the system (Harris et al. 2015). This, in turn, requires leadership at all levels of the system (a key concept within ‘Teaching Scotland's Future' (Scottish Government 2011)) and a purposeful effort to build capacity within the system.

\section{Building capacity at all levels of the system}

Within Scottish education, there has been a clear effort to build capacity within the system, much of it generating from the recommendations of 'Teaching Scotland's Future' (Scottish Government 2014b) and exemplified within the appointment of a team of international experts to offer guidance to the Scottish Government (Seith 2016). However, Harris cautions that systems level reform is heavily dependent 'upon the competence and capability of different parts of the system to respond to the changes required and to connect together' (203) and it could be argued that a 'weak link' in the chain could cause systems reform to falter. The findings of the OECD review of Curriculum for Excellence highlight the need to strengthen 'the middle' (Scottish Government 2015b) - that is, the role that local authorities play in Scottish education. The recent Scottish Government consultation on school governance (to which reference has already been made) will potentially have significant implications with regard to this as one of the key proposals is to shift the locus of power away from the local authority to the level of the school (or clusters of schools).

Building capacity through a focus on leadership preparation with specialised knowledge on disadvantage; re-inforcing coaching and strengthening networks; and attracting great leaders to tough schools (cc. Fig 2), as advocated by Schleicher (2014b), would be an important objective. However this will not suffice if attention is not devoted also to the professional development of teachers such that they develop a 
deep understanding of inclusive pedagogy (as advocated by Florian [2015] ${ }^{\mathrm{iii}}$ ), identifying the barriers to achievement for learners and, with appropriate support and resources, addressing them.

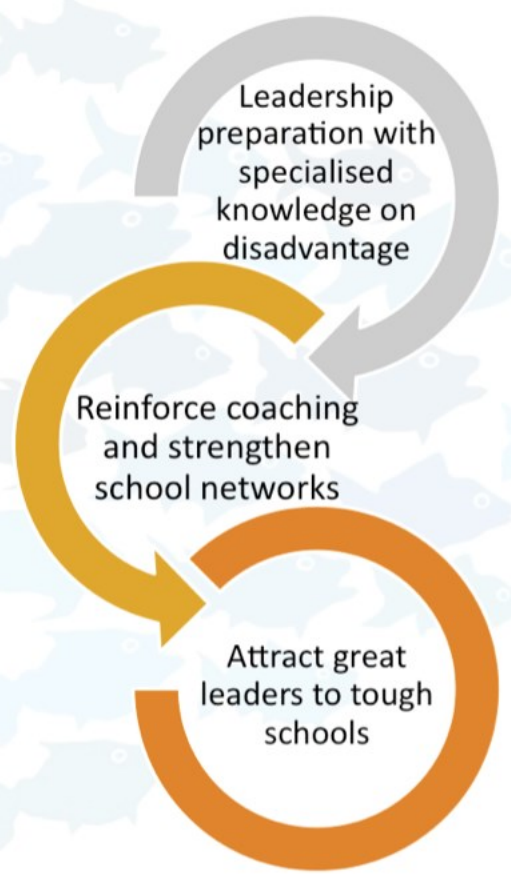

Figure 2: Slide 63 'Strenghen school leadership' (Schleicher, 2014). Reproduced by permission of Andreas Schleicher. ${ }^{\text {iv }}$

What is required is not a narrow focus on 'strategies' but on challenging mindsets, norms and assumptions, bringing people to a new level of understanding, transforming the culture of the school.

\section{A framework for change (and some of the challenges to be overcome)}

This discussion will centre around some of the crucial and critical issues of relevance to the implementation of the policy, relating to the steer given by the Scottish Government to local authorities and schools; the contradictions within the system pulling schools in different directions reflected in the tension between autonomy and accountability; the governance of schools; the need for an evidence-informed, 
sustainable and critical approach; and the need for Higher Education Institutions (HEI) to work in partnership with schools to develop high quality professional development.

\section{The need for a clearer steer from the Scottish Government}

In examining change initiatives which have succeeded in crossing international boundaries, such as those emanating from Harvard University ${ }^{\mathrm{v}}$, what often characterises them is that they derive from a rigorous research base and are based on a framework of principles which guide and direct practice whilst enabling flexibility and innovation at the local level. They are not rigid programmes to be 'lifted from the shelf.'

It could be argued that the National Improvement Framework (NIF) is designed to offer this over-arching set of principles whilst enabling flexibility and the potential for innovation alluded to above. However, closer examination of the document reveals little clear narrative or theoretical perspective (other than its relationship to OECD and other Scottish Government policy documents) nor clear linkage to practice on the ground, other than the evidence to be gathered and how it will inform judgements about improvements made. How did the key underlying principles and the six key drivers - school leadership, teacher professionalism, parental engagement, assessment of children's progress, school improvement and performance information - come to be identified and what is their relationship to each other? The framework has also come under increasing scrutiny and criticism from practitioners and some academics who see it as a return to the strictures of national testing with the concomitant dangers (Seith 2016). 
The need to address contradictions within the system pulling schools in different directions

Relating to the concerns expressed about the strictures of national testing, Ball (2003; 2015) describes an 'epidemic of reform' which is globally driven by marketisation, a culture of managerialism and performativity: 'We come to make decisions about the value of activities and the investment of our time and effort in relation to measures and indexes and the symbolic and real rewards that might be generated from them.' (Ball 2015, 299-300) As such, proxy measures symbolically come to represent the worth of an individual or organisation yet questions remain about who determines what constitutes a 'valuable, effective or satisfactory performance' and the validity of the measures adopted (Ball 2003, 216).

This is reflected within the 'tyranny' of language within educational policy by which terms such as 'outstanding' come to be defined in narrow reductionist ways and are held up as an ideal to which all should aspire (Clapham, Vickers, and Eldridge 2016). It is paralleled in Scotland in a quest for 'excellence' (yet, according to Gillies (2006), despite appearing prominently in the title of the Scottish curriculum, the term is not defined within the policy document).

Teachers are concerned both by the degree to which such proxy measures capture fully and value what they do and also the degree to which a focus upon performativity skews how they teach, leading to short-term strategies for tactical improvement rather than looking for long-term gains (Ball, 2015). A narrowing of the curriculum as 'teachers teach to the test'; restricted skills development and use of pedagogical approaches; and concerns about the use (or abuse) of the data so derived are amongst the concerns raised by a wide range of commentators (Polesel, Rice, and Dulfer 2014). As such, teachers may find themselves conflicted between their genuine 
desire to 'make a difference' for the pupils in their care and central policy directives (Moore and Clark 2016, 675). This conflict manifests itself not only at the level of the individual but also at the level of the organisation (the school) in which a culture of performativity and accountability act both to drive and limit school innovation (Solomon and Lewin 2016). Yet the conundrum is that the greater the degree to which autonomy is 'given' to schools to innovate, the greater the drive towards accountability, as is evidenced within the approach of the Scottish government (and globally).

\section{The need to give consideration to issues pertaining to School Governance}

Education policy in Scotland, whilst emanating from the centre, is devolved to local authorities through local outcome agreements and it could be argued that this form of governance would enable innovation at both vertical and horizontal levels. However, it is not inconceivable that the Scottish Government could be accused of 'throwing money at the problem', leaving local authorities and schools accountable for what then transpires.

\section{The need for an evidence-informed, sustainable and critical approach}

There is a danger of reaching for 'quick fixes' and the making of over-inflated claims as to what specified programmes can achieve. Likewise, hard-pressed leadership teams who are 'time poor' and who are put under pressure to 'deliver' may reach for the 'easy fix' (for example, more computers) rather than the harder more sustainable fix (develop the knowledge, skills and expertise of staff and build a facilitative, participative culture within the school). This implies the need for evidence-informed approaches to guide what schools and teachers do to redress the problem which, in turn, necessitates a 'joined-up approach' with regard to the fostering of a research culture within schools from national bodies such as Education Scotland, the General 
Teaching Council for Scotland (GTCS), the Scottish College for Educational Leadership (SCEL), Higher Education Institutions and research bodies which can ultimately promote more innovative pedagogy and foster a more critical, reflective approach.

The need for HEI providers to work in partnership with schools to develop high quality professional development

There is a danger also that the emphasis on more localised professional development for teachers becomes too inward looking and perpetuates 'more of the same.' As such, there is a need to ensure that HEI providers play a central role in working collaboratively with local authorities and schools in order to build more innovative forms of professional development which are research-informed and foster understanding of the impact of disadvantage on children's lives, otherwise there is a danger of a multiplicity of approaches developing which lack a conceptual base or philosophical underpinnings to guide practice.

This discussion has highlighted some of the major issues that need to be overcome if the Scottish education system is to rise to the challenge.

\section{Final Discussion and Conclusions}

A consistent thread throughout this discussion has been concern about the leverage upon the school as a unit of change and the accountability which this brings with it. Whilst many would agree with the sentiments and intentions of the former Scottish Cabinet Minister's (MSP Angela Constance) message to the teaching profession ‘... it will never be acceptable for poverty to be an excuse for failure. It is our job - the job of everyone in this room - to overcome that barrier, not use it as an excuse' (Constance 2015), it might be perceived by hard-pressed teachers as a criticism of their efforts and a passing of society's problems onto the shoulders of schools and 
teachers. As education has become increasingly politicised across the world, so have expectations of schools and teachers (MacBeath 2012). This is reflected in policies such as, 'No child left behind' (USA); 'Every child matters' (England); 'It's everyone's job to ensure that I'm alright'; the 'Responsibility for all' aspects of Curriculum for Excellence; and the requirement for professionals to take on a guardianship role for all Scottish children, enshrined within the 'Children and Young People (Scotland) Act 2014,vi (Scotland). Such policies, as previously argued, place the accountability on the shoulders of schools and individuals to 'deliver' (very clearly reflected in the language used), in the process negating the wider responsibility of governments to meet social and economic needs.

The problem is compounded by a tendency towards a 'silo approach' in which social problems are seen in isolation of each other, requiring separate solutions (Wilkinson and Pickett 2010). Apple (2012) states, '.. it is important to realize that education is a part of society. It is not something alien, something that stands outside. Indeed, it is a key set of institutions and a key set of social, economic, political, and personal relations' (305). Marcus (2016) argues that 'while schools have an important role in closing the attainment gap, what they contribute is only one aspect of the multi-dimensional efforts across various organisations, policies and practices.'

A range of other commentators concerned about the failure in OECD documentation to relate educational equity to equity more broadly in society argue that schools cannot be expected to address inequities in educational outcome without addressing structural inequalities (Bøyum 2014). However, more recent pronouncements from the OECD seem to be moving more in this direction as exemplified in the following: 'Education's powerful role does not mean that it can work alone. Reducing inequality also requires policies for housing, criminal justice, 
taxation and health care to work hand in hand with education to make a lasting difference' (OECD 2016, 10).

The above is not to imply that schools and teachers should not do everything within their power to address inequalities and to raise aspirations for children and young people nor should be unaccountable for their actions. In keeping with international comparators (OECD 2016a), some Scottish students from impoverished backgrounds, whilst small in number, did 'buck the trend' (Schleicher 2014b). This raises the question - what, within society, the wider community, families, the school environment and individual experience, makes these children and young people more resilient than their counterparts? These are very complex questions with no easy answers or solutions, requiring a bio-ecological perspective ${ }^{\mathrm{vii}}$, a determined, focussed approach in order to address them and mutli-disciplinary research which crosses boundaries. We cannot focus alone on what schools and invidividual teachers can do to address the problem. It needs to be addressed holistically, requiring a systems approach and a critical scrutiny of the range of policies - educational, social and economic - which combine together to create the conditions under which families are living in poverty and which may be culpable in creating the attainment gap in the first instance.

Whilst policy borrowing (and the London Challenge in particular) may appear to offer a potential solution to the problem, the potential barriers to successful transfer need to be understood, highlighting the need to recognise and take account of the mediating effects of culture and context and the limitations of a performativity-driven system, recognising the tensions between competing imperatives. Within this process, power dynamics may impede progress and the 'mix of ingredients' and their 
interaction within a specific context may not necessarily be replicated within the new setting, so making it less likely that the policy will succeed.

The pace of change has emerged as a significant issue. When dealing with an endemic problem which has its roots in generations of families there is a need to take the time to understand the problem before rushing to solutions and to ensure that the solutions forwarded are the right solutions: as argued by MacBeath et al. (2007), we need to take a long-term perspective on it. This means that we need to look beyond the term of a government and try to reach consensus across political parties so that sustainable strategies can be developed and adopted.

All of the above lead to the conclusion that a systems-approach that provides direction from the top but sufficient autonomy at the bottom is necessary if the challenge of addressing the attainment gap is to be overcome. It needs to be an approach that encourages and supports the flourishing of local initiatives and avoids simply 'throwing money at the problem' but doesn't place all of the accountability on schools to deliver. This calls for high quality leadership and capacity building at all levels of the system and investment in people and the professional education of teachers. It also calls for a range of stakeholders, including the third sector and Higher Education Institutions, working effectively together in partnership with schools and local authorities so that the full range of expertise can be drawn upon and research informed practice and collaborative cultures developed.

At both a global and national level, this paper has questioned and critiqued some of the assumptions which underlie system reform and school improvement; understandings of the problem itself and how it has been framed through the policy agenda; and added to the insights relating to how policy 'travels' from one international context to another, highlighting the tensions and dilemmas in the 
process, adding to the body of knowledge within the field. Whilst this paper has not focussed upon the enactment of policy at the local level, the extent to which Scottish Government policy relating to the Scottish Attainment Challenge will become a reality may depend upon the intersection of the policy itself, practice and school positioning (the last of these relating to the stance which the school adopts towards policy enactment) which, according to Braun, Maguire and Ball (2010), are connected and dependent upon each other. This requires a recognition of 'policy as process'; policy practice as 'specific and contextualised' (framed by ethos, culture and individual stances); and mediated by the various 'actors' at each level of the system (ibid.)(as previously argued). What is now required is empirical research to examine how policy unfolds into practice 'on the ground', examining it not only from the perspectives of those instrumental in the formation of the policy but the recipients of it.

\section{References}

One paper has been removed for the purposes of peer review

Adams, P. 2016. "Education policy: explaining, framing and forming." Journal of Education Policy, 31(1): 290-307.

Ainscow, M. 2012. Developing Equitable Education Systems. London: SAGE.

Ainscow, M. 2015. Towards self-improving school systems: lessons from a city challenge. London: Routledge.

Ainscow, M., T. Booth, and A. Dyson. 2006. "Inclusion and the standards agenda: negotiating policy pressures in England." International Journal of Inclusive Education 10 (4-5): 295-308.

Ainscow, M., A. Dyson, S. Goldrick, and M. West. 2016. "Using collaborative inquiry to foster equity within school systems: opportunities and barriers." School Effectiveness and School Improvement 27 (1): 7-23.

Apple, M. W. 2012. Can education change society? London: Routledge.

Ball, S.J. 2003. "The teacher's soul and the terrors of performativity." Journal of Education Policy 18 (2): 215-228.

Ball, S.J. 2015. "Education, governance and the tyranny of numbers." Journal of Education Policy 30 (3): 299-301. 
Bangs, J., Macbeath, J., \& Galton, M. 2011. Re-inventing schools, reforming teaching: From political visions to classroom reality. London: Routledge.

Barber, M., Whelan, F., \& Clark, M. 2007. Capturing the leadership premium: How the world's top school systems are building leadership capacity for the future. London: McKinsey and Company.

Baron, S. 2001. "New Scotland, New Labour, New Community Schools: New authoritarianism?" In Education, Social Justice and Inter-Agency Working: joined-up or fractured policy?, edited by S Riddell and L. Tett, 87-104. London: Routledge.

Bøyum, S. 2014. "Fairness in education - a normative analysis of OECD policy documents." Journal of Education Policy 29 (6): 856-870.

Bradshaw, P 2011. Growing up in Scotland: Changes in child cognitive ability in the pre-school years. Edinburgh: Scottish Government.Barber, M., Whelan, F., \& Clark, M. (2007). Capturing the leadership premium: How the world's top school systems are building leadership capacity for the future. London: McKinsey and Company.

Braun, A., Maguire, M., \& Ball, S. J. (2010). Policy enactments in the UK secondary school: examining policy, practice and school positioning. Journal of Education Policy, 25(4), 547-560. doi: 10.1080/02680931003698544

Coffield, F. (2012). Why the McKinsey reports will not improve school systems. Journal of Education Policy, 27(1), 131-149. doi: 10.1080/02680939.2011.623243

Mourshed, M., C. Chijioke, C., \& M. Barber, M. (2010). How the world's most improved school systems keep getting better: McKinsey and Company.

Schleicher, A. (2014). Equity, Excellence and Inclusiveness in Education. Paper presented at the International Summit on the Teaching Profession, Wellington, New Zealand.

Brunila, K. 2011. "The Projectisation, Marketisation and Therapisation of Education." European Educational Research Journal 10 (3): 421-432.

Burgess, S. 2014. Understanding the success of London's schools. Bristol: Centre for Market and Public Organisation.

Caro, D.H., and P. Mirazchiyski. 2011. "Socioeconomic Gradients in Eastern European Countries: evidence from PIRLS 2006." European Educational Research Journal 11 (1), 96-110.

Clapham, A., R. Vickers, and J. Eldridge. 2016. "Legitimation, performativity and the tyranny of a 'hijacked' word." Journal of Education Policy 31 (6): 757-772.

Coffield, F. 2012. Why the McKinsey reports will not improve school systems. Journal of Education Policy, 27 (1), 131-149.

Constance, Angela MSP. 2015. "Education Secretary Angela Constance speech at Robert Owen Centre." Scottish Government.

Day, S., and S. Hackman. 2012. Strategies to Challenge and Support School Performance in the United Kingdom. San Francisco: WestEd.

Department for Work and Pensions. 2007. Opportunity for all: Indicators update 2007. London: Department for Work and Pensions.

Dickerson, A., and G. Popli. 2012. Persistent poverty and children's cognitive development: Evidence from the UK Millennium Cohort Study. London: Centre for Longitudinal Studies.

Dolowitz, David, P., and David Marsh. 2000. "Learning from Abroad: The Role of Policy Transfer in Contemporary Policy-Making." An International Journal of Policy and Administration 13 (1): 5-24. 
Dumay, X. , and V. Dupriez. 2014. "Educational quasi-markets, school effectiveness and social inequalities." Journal of Education Policy 29 (4): 510-531.

Feniger, Y., and A. Lefstein. 2014. "How not to reason with PISA data: an ironic investigation." Journal of Education Policy 29 (6): 845-855.

Florian, L. 2015. "Inclusive Pedagogy: A transformative approach to individual differences but can it help reduce educational inequalities?" Scottish Educational Review 47 (1): 5-14.

Fullan, M. 2003. Change Forces with a Vengeance. New York: Routledge Falmer.

Gatherer, W. 2013. "Scottish Teachers." In Scottish Education: Fourth Edition: Referendum, edited by T.G.K. Bryce, W.H. Humes, D. Gilies and A. Kennedy. Edinburgh: Edinburgh University Press.

Gillies, D.J.M. 2006. "A Curriculum for Excellence: A Question of Values." Scottish Educational Review 38 (1): 25-36.

Graham, B., and G.B. Slater. 2015. "Education as recovery: neoliberalism, school reform, and the politics of crisis." Journal of Education Policy 30 (1): 1-20.

Greaves, E., L. Macmillan, and L. Sibieta. 2014. Lessons from London schools for attainment gaps and social mobility London: Social Mobility and Poverty Commission.

Grimaldi, Emiliano. 2012. "Neoliberalism and the Marginalisation of Social Justice: The Making of an Education Policy to Combat Social Exclusion." International Journal of Inclusive Education 16 (11): 1131-1154.

Halpin, David, and Barry Troyna. 1995. "The Politics of Education Policy Borrowing." Comparative Education 31 (3): 303-310.

Hargreaves, A., and M. Fullan. 2012. Professional Capital: Transforming Teaching in Every School. London: Routledge.

Harlen, W., and U. Schlapp. 1998. "Literature Reviews." SCRE Spotlight (71).

Harris, A. 2010. "Leading system transformation." School Leadership and Management: Formerly School Organisation 30 (3): 197-207.

Harris, A., D. Adams, M.S. Jones, and V. Muniandy. 2015. "System effectiveness and improvement: the importance of theory and context." School Effectiveness and School Improvement 26 (1): 1-3.

Hill, K., A. Davis, D. Hirsch, and L. Marshall. 2016. Falling short: the experiences of families below the Minimum Income Standard. York: Joseph Rowntree Foundation.

Hirsch, D. 2007. Experiences of poverty and educational disadvantage. York: Joseph Rowntree Foundation.

Hodgson, A., and K. Spours. 2016. "Restrictive and expansive policy learning challenges and strategies for knowledge exchange in upper secondary education across the four countries of the UK." Journal of Education Policy 31 (5): 511-525.

Howieson, C., and C. Iannelli. 2008. "The effects of low attainment on young people's outcomes at age 22-23 in Scotland." British Educational Research Journal, 34 (2): 269-90.

Humes, W. 2001. Examining the role and status of educational research in Scotland (Seminar Report). Edinburgh: Scottish Educational Research Association.

Hutchings, M., C. Greenwood, S. Hollingworth, A. Mansaray, A. Rose, S. Minty, and K. Glass. 2012. Research Report DRE-RR215: Evaluation of the City Challenge Programme. London: Department for Education.

Kidson, M., and E. Norris. 2014. Implementing the London Challenge. London: Institute for Government (supported by Joseph Rowntree Foundation). 
Kingdon, J. 1995. Agendas, alternatives, and public policies. 2nd ed. New York: Longman.

MacBeath, J., Gray, J., Cullen, J., Frost, D., Steward, S., \& Swaffield, S. (2007). Schools on the Edge: Responding to Challenging Circumstances. London: Chapman Publications.

MacBeath, J. 2012. Future of Teaching Profession. Cambridge: Education International Research Institute, University of Cambridge.

MacBeath, John. 2013. "Leading learning in a world of change." In Leadership for 21st Century learning, Educational Research and Innovation, 83-106. Paris, France: OECD Centre for Educational Research and Innovation.

Marcus, G. 2016. Closing The Attainment Gap: What Can Schools Do? In SPICe Briefing. Edinburgh: SPICe The Information Centre, Scottish Government.

Menter, I., F. Payne, D. Christie, and K. Livingston. 2009. Research to Support Schools of Ambition. Edinburgh: Her Majesty's Stationery Office.

Mirza, H.S. 2010. "'Race', gender and educational desire." In Equity, participation and inclusion: Diverse perspectives, edited by J. Rix, M. Nind, K. Sheehy, K. Simmons and C. Walsh. London: Routledge (in partnership with The Open University).

Moore, A., and M. Clarke. 2016. "'Cruel optimism': teacher attachment to professionalism in an era of performativity." Journal of Education Policy 31 (5): 666-677.

Mourshed, M., C. Chijioke, C., \& M. Barber, M. 2010. How the world's most improved school systems keep getting better: McKinsey and Company.

OECD (Organisation for Economic Co-operation and Development). 2007. Reviews of National Policies for Education: Quality and Equity of Schooling in Scotland. Paris, France: OECD Centre for Educational Research and Innovation.

OECD (Organisation for Economic Co-operation and Development). 2013. Leadership for 21st Century Learning. Paris, France: OECD Centre for Educational Research and Innovation.

OECD (Organisation for Economic Co-operation and Development). 2016a. PISA 2015 Results: Excellence and Equity in Education (Vol. 1). Paris, France: OECD Centre for Educational Research and Innovation.

OECD (Organisation for Economic Co-operation and Development). 2016b. Trends Shaping Education Spotlight 8: Mind the Gap: Inequity in Education. Paris, France: OECD Centre for Educational Research and Innovation.

Philips, D., and K. Ochs. 2003. "Processes of Policy Borrowing in Education: some explanatory and analytical devices." Comparative Education 39 (4): 451-461.

Philips, D., and K. Ochs. 2004. "Researching policy borrowing: some methodological challenges in comparative education." British Educational Research Journal 30 (6): 773-784.

Philips, David. 2006. "Investigating policy attraction in education." Oxford Review of Education 32 (5): 551-559.

Polesel, J., S. Rice, and N. Dulfer. 2014. "The impact of high-stakes testing on curriculum and pedagogy: a teacher perspective from Australia." Journal of Education Policy 29 (5): 640-657.

Policy First. 2012. Breaking Down Barriers: How we can ensure no child's educational success is limited by their socio-economic background. London: Policy First. 
Pont, B. , D. Nusche, and H. Moorman. 2008. Improving School Leadership: Volume 2: Case Studies on System Leadership. Paris, France: OECD Centre for Educational Research and Innovation.

Prince, Emily Jane, and Julie Hadwin. 2013. "The role of a sense of school belonging in understanding the effectiveness of inclusion of children with special educational needs." International Journal of Inclusive Education 17 (3): 238262.

Reynolds, D. 2010. Failure-free education? The past, present and future of school effectiveness and school improvement. London: Routledge.

Ridge, Tess. 2011. "The Everyday Costs of Poverty in Childhood: A Review of Qualitative Research Exploring the Lives and Experiences of Low-Income Children in the UK." Children and Society 25 (1): 73-84.

Riglin, L, N Frederickson, K.H Shelton, and F. Rice. 2013. "A longitudinal study of psychological functioning and academic attainment at the transition to secondary school." Journal of Adolescence 36 (3): 507-517.

Ringarp, Johanna, and Martin Rothland. 2010. "Is the grass always greener...? The Effect of the PISA Results on Education Debates in Sweden and Germany." European Educational Research Journal 9 (3): 422 - 430.

Rizvi, F., and B. Lingard. 2010. Globalising Education Policy. London: Routledge.

Smith [RH], I. D. 2015. Government to strengthen child poverty measure. London: Department for Work and Pensions.

Schleicher, A. 2014a. "Equity, Excellence and Inclusiveness in Education." Paper presented at the International Summit on the Teaching Profession, Wellington, New Zealand, March 28.

Schleicher, A. 2014b. Equity, Excellence and Inclusiveness in Education: Policy Lessons from Around the World: Background report for the 2014 International Summit of the Teaching Profession. Paris, France: OECD Centre for Educational Research and Innovation.

SEED (Scottish Executive Education Department). 2001. Raising Attainment of Children with Special Educational Needs. Edinburgh: Her Majesty's Stationery Office.

SEED (Scottish Executive Education Department). 2002. It's everyone's job to make sure that I'm alright. Edinburgh: Her Majesty's Stationery Office.

SEED (Scottish Executive Education Department). 2004. Ambitious, Excellent Schools: our agenda for action. Edinburgh: Her Majesty's Stationery Office.

SEED (Scottish Executive Education Department). 2007. OECD Review of the Quality and Equity of Education Outcomes in Scotland: Diagnostic Report. Edinburgh: Her Majesty's Stationery Office.

Scottish Government. 2011. Teaching Scotland's Future - Report of a review of teacher education in Scotland. Edinburgh: Scottish Government.

Scottish Government. 2012. Supporting Children's and Young People's Learning: A Report on Progress of Implementation of The Education (Additional Support for Learning) (Scotland) Act 2004 (As Amended). Edinburgh: Scottish Government.

Scottish Government. 2013. Scottish Survey of Literacy and Numeracy 2012 (literacy). Edinburgh: Scottish Government.

Scottish Government. 2014a. Child Poverty Strategy for Scotland: Our approach 2014-2017. Edinburgh: Scottish Government.

Scottish Government. 2014b. Teaching Scotland's Future Update. Edinburgh: Education Scotland. 
Scottish Government. 2015a. "Growing up in Scotland: Tackling inequalities in the early years: Key messages from 10 years of the Growing Up in Scotland study" Growing Up in Scotland Event, Edinburgh, October 7.

Scottish Government. 2015b. Improving Schools in Scotland: an OECD perspective. Edinburgh: Scottish Government.

Scottish Government. 2016a. Delivering Excellence and Equity in Scottish Education: A Delivery Plan for Scotland. Retrieved from http://www.gov.scot/Publications/2016/06/3853.

Scottish Government. 2016b. Empowering teachers, parents and communities to achieve excellence and equity in education: a governance review. Edinburgh: Scotish Government.

Scottish Government. 2016c. National Improvement Framework for Scottish Education: Achieving excellence and equity. Edinburgh: Scottish Government.

Scottish Government. 2016d. Education Outcomes for Scotland's Looked After and Accommodated Children 2013-2014. Edinburgh: Scottish Government.

Scottish Government. 2016e. A Blueprint for Fairness: The final report on widening access. Edinburgh: Scottish Government.

Seith, E. 2016. "World experts assemble to oversee Scotland's reforms." Times Educational Supplement Scotland, $15^{\text {th }}$ July.

Seith, Emma. 2015. "We all have lessons to learn about disadvantage." Times Educational Supplement Scotland, 17th July.

Seith, E. 2016. Tories insist that testing at age 5 is 'too young'. Times Educational Supplement Scotland, $1^{\text {st }}$ July.

Shaw, B., E. Bernardes, A. Trethewey, and L. Menzies. 2016. Special educational needs and their links to poverty. York: Joseph Rowntree Foundation.

Smyth, J., and T. Wrigley. 2013. Living on the Edge: Rethinking Poverty, Class and Schooling. Edited by J.L. DeVities and L. Irwin-DeVitis, Adolescent Cultures, School and Society. Oxford: Peter Lang.

Solomon, Y., and C. Lewin. 2016. "Measuring 'progress': performativity as both driver and constraint in school innovation." Journal of Education Policy 31 (2): 226-238.

Sosu, Edward, and Sue Ellis. 2014. Closing the Attainment Gap in Scottish Education. York: Joseph Rowntree Foundation.

Spillane, James, P. 2013. "The practice of leading and managing teaching in educational organisations." In Leadership for 21st Century learning, Educational Research and Innovation, 59-82. Paris, France: OECD Centre for Educational Research and Innovation.

Steiner-Khamsi, G. 2006. "The economics of policy borrowing and lending: a study of late adopters." Oxford Review of Education 32 (5): 665-678.

Steiner-Khamsi, G. 2014. "Cross-national policy borrowing: understanding reception and translation." Asia Pacific Journal of Education 34 (2): 153-167.

Taylor, Y. 2010. "Brushed behind the bike shed: working class lesbians' experience of school " In Equality, Participation and Inclusion, edited by J. Rix, M. Nind, K. Sheehy, K. Simmons and C. Walsh, 286-94. London: The Open University.

The New Policy Institute. 2013. Monitoring Poverty and Social Exclusion in Scotland. York: Joseph Rowntree Foundation.

Tomlinson, Mike. 2013. "How London Challenge turned capital's schools around." The Guardian. http://www.theguardian.com/politics/2013/dec/11/londonchallenge-turned-poor-schools-around.

Wilkinson, R., \& Pickett, K. 2010. The Spirit Level: Why equality is better for 
everyone. London: Penguin Books.

Willms, J.D. 1999. "Quality and inequality in children's literacy: the effects of families, schools, and communities." In Developmental Health and the Wealth of Nations, edited by D. P. Keating and C. Hertzman, 72-93. New York: Guilford Press.

Valant, J., and D.A. Newark. 2016. "The politics of achievement gaps: U.S. public opinion on race-based and wealth-based differences in test-scores."

Educational Researcher 45 (6): 331-346.

Wrigley, Terry. 2012. "Achievement, poverty and privatisation in England: Policy and evidence." Improving Schools 15 (1): 5-9.

\section{Notes}

\footnotetext{
${ }^{\mathrm{i}}$ The Joseph Rowntree Foundation draw upon Peter Townsend's definition of relative poverty as being 'when someone's resources are so seriously below those commanded by the average individual or family that they are, in effect, excluded from ordinary living patterns, customs and activities.' https://www.jrf.org.uk/sites/default/files/jrf/migrated/files/poverty-definitions.pdf

${ }^{\text {ii }}$ Such as PISA, TIMSS (Trends in International Mathematics and Science Study) and PIRLS (Progress in International Reading Literacy Study)

iii Florian describes inclusive pedagogy as being "concerned with redressing the limitations on learning that are often inadvertently placed on children when they are judged 'less able'. It does not deny differences between learners but seeks to accommodate them by extending what is ordinarily available to all rather than by differentiating for some.' (Florian 2015, 13)

iv Reproduced with kind permission of Andreas Schleicher

$\mathrm{v}$ The series of projects emanating from Project Zero

${ }^{v i}$ The 'named person' component of the Act has been challenged through the courts with a judgement announced on the $28^{\text {th }}$ of July 2016

vii Bronfenbrenner, U., \& Morris, P. A. (2006). The bioecological model of human development. In R. M. Lerner (Ed.), Handbook of Child Psychology: Theoretical Models of Human Development (6th ed., Vol. 1, pp. 793-828). Hoboken: NJ: Wiley.
} 